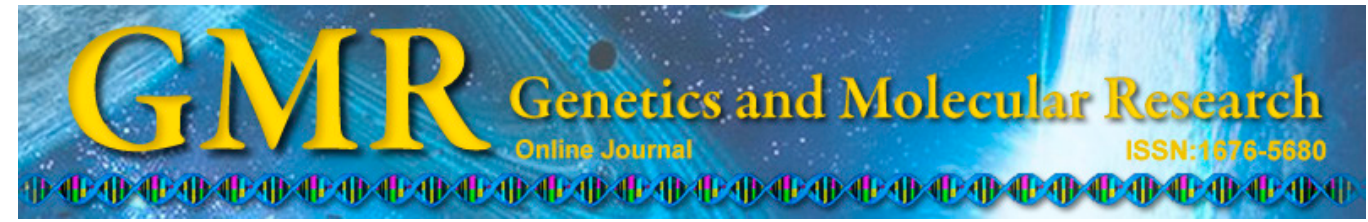

\title{
Association of the C677T polymorphism in the methylenetetrahydrofolate reductase gene with breast cancer in a Mexican population
}

\author{
A. Ramos-Silva ${ }^{1,2}$, L.E. Figuera ${ }^{3}$, O.M. Soto-Quintana ${ }^{1,2}$, A.M. Puebla-Pérez ${ }^{4}$, \\ R. Ramírez-Patiño ${ }^{1,5}$, I. Gutiérrez-Hurtado ${ }^{1,5}$, D.I. Carrillo-Moreno ${ }^{1,5}$, \\ G.M. Zúñiga-González ${ }^{6}$, I.P. Dávalos-Rodríguez ${ }^{3}$ and M.P. Gallegos-Arreola ${ }^{1}$
}

${ }^{1}$ Genetics Molecular Laboratory, Molecular Medicine Division, Western Biomedical Research Center, Western National Medical Center, Mexican Institute of Social Security, Guadalajara, Jalisco, Mexico ${ }^{2}$ Doctorate Programm in Pharmacology, Health Sciences University Center, University of Guadalajara, Guadalajara, Jalisco, Mexico ${ }^{3}$ Genetics Division, Western Biomedical Research Center, Western National Medical Center, Guadalajara, Jalisco, México ${ }^{4}$ Inmmunopharmacology Laboratory,

Exact and Engineering Sciences University Center, University of Guadalajara, Guadalajara, Jalisco, México

${ }^{5}$ Doctorate Programm in Human Genetics, Health Sciences University Center, University of Guadalajara, Guadalajara, Jalisco, México

${ }^{6}$ Mutagenesis Laboratory, Molecular Medicine Division, Western Biomedical Research Center, Western National Medical Center, Mexican Institute of Social Security, Guadalajara, Jalisco, Mexico

Corresponding author: M.P. Gallegos-Arreola

E-mail: marthapatriciagallegos08@gmail.com

Genet. Mol. Res. 14 (2): 4015-4026 (2015)

Received June 18, 2014

Accepted October 9, 2014

Published April 27, 2015

DOI http://dx.doi.org/10.4238/2015.April.27.16

ABSTRACT. The methylenetetrahydrofolate reductase (MTHFR) gene plays an important role in the steps involved in the processing of amino acids. The analysis of polymorphisms in the MTHFR gene has revealed associations with cancer; in particular the C677T 
polymorphism, which has been suggested to affect folate metabolism, DNA methylation, synthesis, and repair, and to contribute to tumor promotion in the mammary gland. We examined the role of the C677T polymorphism in the MTHFR gene by comparing the C677T genotypes of 339 healthy Mexican women with those of 497 Mexican women with breast cancer $(\mathrm{BC})$. The genotype frequencies observed in the controls and patients with BC were 10 and $21 \%$ for $677 \mathrm{TT}$; 41 and $36 \%$ for $677 \mathrm{CT}$; and 49 and $43 \%$ for $677 \mathrm{CC}$, respectively. The odds ratio (OR) for the $677 \mathrm{TT}$ genotype was 2.5 , with a $95 \%$ confidence interval $(95 \% \mathrm{CI})$ of $1.6-3.8 ; \mathrm{P}=0.0001$. The positive association was also evident when the distributions of the 677TT genotype in control and patients affected within the following two categories were compared to alcohol consumption $(\mathrm{OR}=0.41 ; 95 \% \mathrm{CI}=0.19-0.86 ; \mathrm{P}=0.018)$; and high level glutamate-oxaloacetate transaminase (SGOT) $(\mathrm{OR}=0.36$; $95 \% \mathrm{CI}=0.15-0.83, \mathrm{P}=0.017)$. These results suggest that the 677TT genotype of the C677T polymorphism in the MTHFR gene is associated with $\mathrm{BC}$ susceptibility in the Mexican population.

Key words: MTHFR; C677T polymorphism; Breast cancer; Mexican population

\section{INTRODUCTION}

Breast cancer $(\mathrm{BC})$ is one of the most common diseases in developing countries and around the world (Abdulrahman and Rahman, 2012; Siegel et al., 2012). The incidence rates of cancer vary across ethnic groups (Miller et al., 2010; Abdulrahman and Rahman, 2012). In many countries, particularity in Mexico, the incidence of $\mathrm{BC}$ has increased within the last seven years, and it is now one of the main causes of death for working age women (Chávarri et al., 2012). The state of Jalisco exhibits one of the highest mortalities associated with BC, with only 10\% of all cases of BC detected at stage I (Knaul et al., 2009; Gómez Flores et al., 2013; Ramírez et al., 2013; Gallegos et al., 2014). BC is considered a multifactorial disease resulting from a combination of abnormal gene interactions and environmental factors (Gallegos et al., 2009; Gómez Flores et al., 2013; Ramírez et al., 2013; Gallegos et al., 2014). Therefore, elucidating genetic variants associated with $\mathrm{BC}$ among different ethnic groups could contribute to a better overall understanding of cancer progression as well as chemotherapy response.

The relationship between plasma folate levels, uracil content, and DNA damage in dividing cells renders methylenetetrahydrofolate reductase (MTHFR) a suitable candidate for studies of cancer susceptibility including in BC (Gallegos et al., 2009). The MTHFR gene, located on chromosome 1p36.3, is comprised of eleven exons and ten introns (OMIM 607093). MTHFR encodes the 5,10-methyl-tetrahydrofolate enzyme, which catalyzes the conversion of 5,10-methyl-THF to 5-methyl-THF. This enzyme has an important regulatory function in folate metabolism, where it directs the folate pool to remethylate homocysteine at the expense of DNA and RNA synthesis (Gallegos et al., 2009). Several polymorphisms have been reported in the MTHFR gene, one of which, C677T (pAla222Val) in exon 4, encodes a thermolabile variant of the protein that reduces its global activity (Gallegos et al., 2009). It has been reported that he MTHFR C677T variant results in a thermo labile protein with enzymatic activity that 
is decreased by $35 \%$ in the heterozygote state (CT genotype) and by $70 \%$ in the homozygote state (TT genotype). People with the thermolabile form of the enzyme have increased levels of homocysteine in their blood (Zetterberg et al., 2002). These functional results, therefore, suggest that the presence of 677TT genotype may lead to decompensation of intracellular folate distribution, and could promote the retention of folate needed for purine and pyrimidine synthesis. Evidence of an association between the C677T polymorphism and an increased risk of developing malignancies (including BC) has been reported (Isotalo and Donnelly, 2000; Papandreou et al., 2012; Weiwei et al., 2014; Liang et al., 2014). Papandreou et al. (2012) found a high frequency of the "T" allele in patients with BC patients in a Greek population. Weiwei et al. (2014) observed a significant interaction between the MTHFR C667T polymorphism and folate intake on the risk of $\mathrm{BC}(\mathrm{P}=0.025)$, and Liang et al. (2014) found that the MTHFR C677T polymorphism was significantly associated with $\mathrm{BC}$ risk in the Chinese population.

It has also been observed that the frequency of the C677T polymorphic variant varies between diverse ethnic groups. In Dutch and Canadian populations, the frequencies were 8.5 and $12 \%$, respectively; other reported frequencies include $10 \%$ in Caucasians; and $20 \%$ in Italians (Kluijtmans et al., 1997; Isotalo and Donnelly, 2000; Gallegos et al., 2009). Several reports studying the general Mexican population have described high frequencies of the C677T variant, ranging from 19.7 to 34\% depending upon the area of Mexico investigated (Davalos et al., 2000; Esfahani et al., 2003; Gueant et al., 2006; Gallegos et al., 2008, 2009). However, there are no descriptions of an association of the MTHFR C677T polymorphism in Mexican women with BC.

\section{MATERIAL AND METHODS}

\section{Patient and sample information}

DNA was extracted from peripheral blood lymphocytes isolated from blood samples collected from 339 healthy women recruited as volunteer blood donors using standard protocols (Miller et al., 1988). These volunteers were not matched by age with the patient group. Blood samples were also collected from 497 patients with a clinical and histological diagnosis of BC from June 2010 to April 2014. All of the individuals included in this study were residents of the metropolitan area of Guadalajara. All samples were obtained after a written informed consent form was signed, which was previously approved by ethical committees 1231 and 1305 of the Western Biomedical Research Center, Mexican Institute of Social Security, Guadalajara, Jalisco, Mexico.

This study was conducted respecting the national and international ethical standards. Efforts were made to ensure that siblings of individuals who had already been sampled were excluded. Clinical and demographical data were obtained using written questionnaires. All of the patients were also interviewed to determine their occupational exposure and as well as use of pharmacological therapies. The BC patient database and their DNA samples had previously been examined for other polymorphisms (Gómez Flores et al., 2013; Ramírez et al., 2013; Gallegos et al., 2013).

\section{MTHFR C677T polymorphism genotyping}

Amplification of the MTHFR C677T polymorphism was performed via the poly- 
merase chain reaction (PCR) using the following primers: 5'-CCT TGA ACA GGT GGA GGC C-3' and 5'-CAA AGA AAA GCT GCG TGA TGA T-3' (Gallegos et al., 2008, 2009). PCR amplifications were performed in $15 \mu \mathrm{L}$ total volume containing $0.2 \mathrm{mM}$ dNTPs (Invitrogen, Carlsbad, CA, USA), $5 \mathrm{pM}$ primers, $1.5 \mathrm{mM} \mathrm{MgCl}$, $1.5 \mathrm{U}$ Taq polymerase (Invitrogen), and $50 \mathrm{ng}$ genomic DNA. The PCR conditions were as follows: $94^{\circ} \mathrm{C}(4 \mathrm{~min})$, followed by 35 cycles at $94^{\circ} \mathrm{C}(1 \mathrm{~min}), 55^{\circ} \mathrm{C}(1 \mathrm{~min})$ and $72^{\circ} \mathrm{C}(1 \mathrm{~min})$, with a final extension at $72^{\circ} \mathrm{C}(7$ $\mathrm{min}$ ). The 158-bp long amplicon was digested with the HinfI restriction enzyme (Promega, Madison, WI, USA) at $37^{\circ} \mathrm{C}$ for $12 \mathrm{~h}$. Allele discrimination was performed using $8 \%$ polyacrylamide gel (19:1) electrophoresis, followed by silver staining (Sanguinetti et al., 1994). Reduction of the amplicon to 130- and 28-bp fragments indicated a polymorphic variant-type genotype (677TT), whereas a single undigested fragment of $158 \mathrm{bp}$ indicated the wild-type genotype (677CC).

\section{Statistical analysis}

Allele frequencies were obtained by direct counting. Hardy-Weinberg equilibrium was tested using a goodness-of-fit chi square test to compare the observed genotype frequencies to those expected among control subjects. Odds ratios and $95 \%$ confidence intervals (CIs) were also calculated. A two-sided $\mathrm{P}<0.05$ was considered to be statistically significant. All statistical analyses were performed using the PASW Statistic Base 18 software, 2009 (SPSS, Chicago, IL, USA).

\section{RESULTS}

The comparative epidemiological data from patients with $\mathrm{BC}$ and control individuals are shown in Table 1. The average ages were 53.26 and 33.64 years in the patient and control groups, respectively. Menarche presented at a mean age of 12.71 years in the patients and at 12.25 years in the controls. Oral contraceptive use $(\mathrm{OR}=5.5 ; 95 \% \mathrm{CI}=3.2-9.5 ; \mathrm{P}<0.0001)$, abortion $(\mathrm{OR}=$ $2.1,95 \% \mathrm{CI}=1.1-4.0 ; \mathrm{P}=0.013)$, breastfeeding $\leq 6$ months $(\mathrm{OR}=0.04 ; 95 \% \mathrm{CI}=0.004-0.31 ; \mathrm{P}$ $=0.002)$, menopause $(\mathrm{OR}=16 ; 95 \% \mathrm{CI}=9.9-26.3 ; \mathrm{P}<0.0001)$, and positive familial history of $\mathrm{BC}$, diabetes mellitus-arterial hypertension (DM-AH), and DM-AH-Cancer in first and second degree relatives of patients $(\mathrm{P}=0.0001)$ were observed to be risk factors. Conversely, alcohol consumption was a protective factor $(\mathrm{OR}=0.38 ; 95 \% \mathrm{CI}=0.21-0.69, \mathrm{P}=0.001)$.

Table 2 provides the general clinical characteristics of the patient group. We observed that $27 \%$ of the patients exhibited DM-AH; $19 \%$ presented with breast fibrosis-miomatosishysterectomy; 47\% were Luminal A positive; $89 \%$ displayed ductal histology; and $62 \%$ exhibited stage III-IV tumors. Additionally, approximately $19 \%$ of the patients presented with high levels of glutamate oxaloacetate transaminase (SGOT), and more than $20 \%$ showed high levels of alkaline phosphatase (ALP) and glucose.

Table 3 summarizes the results of the multivariate logistic regression analysis, where the $\mathrm{BC}$ group was classified as presenting with tumor stages I-II or III-IV as the dependent variable. An obesity grade of II $(\mathrm{OR}=2.3 ; 95 \% \mathrm{CI}=1.2-4.2 ; \mathrm{P}=0.008)$, metastatic nodules $(\mathrm{OR}=1.9 ; 95 \% \mathrm{CI}=1.2-3.1 ; \mathrm{P}=0.002)$, metastases $(\mathrm{OR}=7.0 ; 95 \% \mathrm{CI}=4.2-11.7 ; \mathrm{P}=0.000)$, and tobacco consumption $(\mathrm{OR}=2.0 ; 95 \% \mathrm{CI}=1.1-3.4, \mathrm{P}=0.010)$ were found to be risk factors associated with stage III-VI tumors. 


\begin{tabular}{|c|c|c|c|c|c|c|}
\hline \multirow[b]{2}{*}{ Age (years) } & \multicolumn{2}{|c|}{ BC patients $(\mathrm{N}=497)$} & \multicolumn{2}{|c|}{ Controls $(\mathrm{N}=339)$} & \multirow[t]{2}{*}{ OR $(95 \% \mathrm{CI})^{*}$} & \multirow[t]{2}{*}{$P$ value } \\
\hline & & & & & & \\
\hline Means (SD) & 53.26 & (11.65) & 33.64 & $(10.9)$ & & $<0.0001$ \\
\hline \multirow{3}{*}{$\begin{array}{l}\text { Menarche (years) } \\
\text { Means (SD) }\end{array}$} & & & & & & \\
\hline & 12.71 & $(1.6)$ & 12.25 & (1.3) & & $<0.0001$ \\
\hline & (N) & $\%$ & $(\mathrm{~N})$ & $\%$ & & \\
\hline \multicolumn{7}{|l|}{ Menarche (range) } \\
\hline $7-10$ & (35) & 7 & $(15)$ & 4 & & \\
\hline $11-13$ & (318) & 64 & (262) & 77 & & \\
\hline $14-18$ & (144) & 29 & $(62)$ & 19 & & \\
\hline \multicolumn{7}{|l|}{ Oral contraceptive use } \\
\hline Yes & (208) & 42 & (48) & 14 & $5.5(3.2-9.5)$ & $<0.0001$ \\
\hline No & (289) & 58 & (291) & 86 & & \\
\hline \multicolumn{7}{|l|}{ Abortion } \\
\hline Yes & (141) & 28 & (34) & 9 & $2.1(1.1-4.0)$ & 0.013 \\
\hline No & (356) & 72 & (305) & 91 & & \\
\hline \multicolumn{7}{|l|}{ Breastfeeding } \\
\hline$\leq 6$ months & $(56)$ & 11 & (130) & 38 & $0.04(0.004-0.31)$ & 0.002 \\
\hline$>6$ months & (252) & 51 & (48) & 14 & & \\
\hline No & (189) & 38 & (161) & 48 & & \\
\hline \multicolumn{7}{|l|}{ Menopause } \\
\hline Postmenopausal & (329) & 66 & (45) & 13 & $16(9.9-26.3)$ & $<0.0001$ \\
\hline Premenopausal & (168) & 34 & (294) & 87 & & \\
\hline \multicolumn{7}{|l|}{ Tobacco consumption } \\
\hline Yes & (132) & 27 & (74) & 22 & & NS \\
\hline No & (365) & 73 & (265) & 78 & & \\
\hline \multicolumn{7}{|l|}{ Alcohol consumption } \\
\hline Yes & (76) & 15 & (75) & 28 & $0.38(0.21-0.69)$ & 0.001 \\
\hline No & (421) & 85 & (264) & 72 & & \\
\hline \multicolumn{7}{|l|}{ Familial history (FH) } \\
\hline No & (174) & 35 & (267) & 79 & & \\
\hline $\mathrm{BC}$ & (59) & 12 & (8) & 2 & $13.4(4.8-37.2)$ & 0.0001 \\
\hline DM-AH & (134) & 27 & (37) & 11 & $4.3(2.3-8.1)$ & 0.0001 \\
\hline DM-AH-Cancer** & (130) & 26 & (27) & 8 & $5.3(2.7-10.2)$ & 0.0001 \\
\hline
\end{tabular}

SD (standard deviation), NS (no significant difference), *OR (odds ratio) from the adjusted regression analysis, ** positive familial history of cancer and leukemia in first and second degree relatives of patients.

The genotype and allele frequencies of the MTHFR gene C677T polymorphism were different in the control and patient groups (Table 4). The polymorphic variant genotype $(677 \mathrm{TT})$ was observed in $21 \%(103 / 497)$ of patients and in $10 \%(32 / 339)$ of controls (OR $=2.5 ; 95 \% \mathrm{CI}=1.6-3.8, \mathrm{P}=0.0001)$. The genotype distribution in the control group was in Hardy-Weinberg equilibrium. All of the samples were analyzed, and all of the participants' genotypes (for 339 controls and $497 \mathrm{BC}$ patients) were obtained.

Table 5 shows that the 677TT genotype was associated with alcohol consumption $(\mathrm{OR}=0.41 ; 95 \% \mathrm{CI}=0.199-0.86 ; \mathrm{P}=0.018)$ and high level $\mathrm{SGOT}(\mathrm{OR}=0.36 ; 95 \% \mathrm{CI}=$ $0.15-0.83 ; \mathrm{P}=0.017)$, and the variables listed in Tables 1 and 2 were found to be protective factors.

In addition, we observed that the 677TT variant genotype served as a protective factor in the chemotherapy response of $\mathrm{BC}$ patients who were positive for alcohol consumption, high level SGOT $(\mathrm{OR}=0.29 ; 95 \% \mathrm{CI}=0.10-0.8 ; \mathrm{P}=0.016)$, and triple negative classification [defined by lack of expression of estrogen receptor (ER) and of progesterone receptor (PR) and lack of amplification or overexpression of human epidermal growth factor receptor $2(\mathrm{HER} 2)](\mathrm{OR}=0.49 ; 95 \% \mathrm{CI}=0.20-0.9 ; \mathrm{P}=0.043)$ (data not shown). 
Table 2. Clinical data from patients with BC.

\begin{tabular}{|c|c|c|c|c|c|}
\hline & $\mathrm{N}$ & $\%$ & & $(\mathrm{~N})$ & $\%$ \\
\hline Personal medical history & & & Chemotherapy type & & \\
\hline No & (255) & 51 & FEC & (385) & 77 \\
\hline DM-AH & (134) & 27 & Other & (92) & 19 \\
\hline Breast, fibrosis, miomatosis & (94) & 19 & No chemotherapy & (20) & 4 \\
\hline Depression, pregnancy, asthma & (14) & 3 & Laboratory test & & \\
\hline Body Mass Index (BMI)* & & & Hemoglobin $(\mathrm{g} / \mathrm{dL})$ & & \\
\hline $18.5-24.9$ (normal) & (94) & 19 & $<11$ & (95) & 19 \\
\hline$\geq 25-29.9$ (overweight) & (179) & 36 & $11-16.4$ & (402) & 81 \\
\hline$\geq 30-34.9$ (obesity I) & (132) & 27 & Hematocrit (\%) & & \\
\hline$\geq 35->40$ (obesity II- IV) & $(92)$ & 18 & $<37$ & (94) & 19 \\
\hline Tumor localization & & & $37-47$ & (403) & 81 \\
\hline Unilateral & (474) & 95 & Platelets $\left(\mathrm{mm}^{3}\right)$ & & \\
\hline Bilateral & (23) & 5 & $<150,000$ & (18) & 4 \\
\hline Diagnostic time & & & $150,000-450,000$ & (341) & 69 \\
\hline $1-4$ years & (367) & 74 & $>450,000$ & (138) & 27 \\
\hline 5-9 years & (107) & 22 & Leukocytes $\left(\mathrm{mm}^{3}\right)$ & & \\
\hline $10-15$ years & (23) & 4 & $<150,000$ & (53) & 11 \\
\hline Tumor markers & & & $150,000-500,000$ & (444) & 89 \\
\hline Luminal A & (236) & 47 & $\mathrm{SGOT}(\mu \mathrm{I} / \mathrm{L})$ & & \\
\hline Luminal B & (87) & 18 & $>35$ & (93) & 19 \\
\hline Her2/neu & $(58)$ & 12 & $0-35$ & (404) & 81 \\
\hline Basal & (116) & 23 & $\operatorname{SGPT}(\mu \mathrm{I} / \mathrm{L})$ & & \\
\hline Histology & & & $>45$ & $(52)$ & 10 \\
\hline Ductal & (438) & 89 & $5-45$ & (446) & 90 \\
\hline Lobular & (53) & 10 & $\mathrm{LDH}(\mu \mathrm{I} / \mathrm{L})$ & & \\
\hline Mixed & (6) & 1 & $>333$ & (75) & 15 \\
\hline Tumor stage & & & $105-333$ & (422) & 85 \\
\hline I-II & (191) & 38 & $\operatorname{ALP}(\mu \mathrm{I} / \mathrm{L})$ & & \\
\hline III-IV & (306) & 62 & $>45$ & (107) & 22 \\
\hline Lymph node status & & & $5-45$ & (390) & 76 \\
\hline Yes & (355) & 71 & $\mathrm{GGT}(\mu \mathrm{I} / \mathrm{L})$ & & \\
\hline No & (144) & 20 & $>45$ & (123) & 15 \\
\hline Metastasis & & & $5-45$ & (374) & 75 \\
\hline Yes & (174) & 35 & Glucose $(\mu \mathrm{I} / \mathrm{L})$ & & \\
\hline No & (323) & 65 & $>106$ & (142) & 29 \\
\hline Chemotherapy response & & & $74-106$ & (355) & 71 \\
\hline Yes & (317) & 64 & & & \\
\hline No & (180) & 36 & & & \\
\hline
\end{tabular}

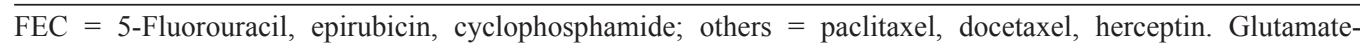
oxaloacetate transaminase (SGOT), glutamic pyruvic transaminase (SGPT), lactate dehydrogenase (LDH), alkaline phosphatase (ALP), gamma glutamyltransferase (GGT), *according to OMS classifications (World Health Organization, 2004).

Table 3. Binary logistic regression analysis of the patient group.

\begin{tabular}{|c|c|c|c|c|c|c|c|c|}
\hline & \multirow[t]{2}{*}{$\mathrm{B}$} & \multirow[t]{2}{*}{ SD } & \multirow[t]{2}{*}{ Wald } & \multirow[t]{2}{*}{$\mathrm{df}$} & \multirow[t]{2}{*}{$\mathrm{P}$} & \multirow[t]{2}{*}{ OR } & \multicolumn{2}{|c|}{$95 \% \mathrm{CI}$} \\
\hline & & & & & & & Lower limit & Upper limit \\
\hline Obesity grade II & 0.837 & 0.316 & 7.013 & 1 & 0.008 & 2.309 & 1.243 & 4.288 \\
\hline Lymph node status & 0.692 & 0.226 & 9.401 & 1 & 0.002 & 1.998 & 1.284 & 3.111 \\
\hline Metastasis & 1.956 & 0.260 & 56.559 & 1 & 0.000 & 7.070 & 4.247 & 11.771 \\
\hline Tobacco consumption & 0.696 & 0.270 & 6.633 & 1 & 0.010 & 2.005 & 1.181 & 3.404 \\
\hline Constant & -0.702 & 0.215 & 10.638 & 1 & 0.001 & 0.496 & & \\
\hline
\end{tabular}

Variables included in the analysis: dependent: BC classified by tumor status as stage I-II or III-IV; independent: personal medical history, menarche ranging from 7-10 years, 11-13 years, or 14-18 years; menopause, pregnancies, breastfeeding, oral contraceptive use, tobacco and alcohol consumption, a BMI of 18.5-24.9, $\geq 25-29.9, \geq 30-34.9$, or (obesity grade II-IV) $\geq 35->40$, lymph node status, metastasis, response to chemotherapy, laboratory tests (HB, HTO, platelets, leukocytes, urea, SGOT, SGPT, LDH, ALP, GGT, and glucose). 
Table 4. Genotype and allelic distribution of the C677T polymorphism of the MTHFR gene in healthy controls and $\mathrm{BC}$ patients.

\begin{tabular}{|c|c|c|c|c|c|c|c|}
\hline & \multicolumn{2}{|c|}{ Patients (497) } & \multicolumn{2}{|c|}{ Controls (339)* } & \multicolumn{3}{|c|}{ Patients $v s$ Controls } \\
\hline & $(\mathrm{N})$ & $\%$ & $(\mathrm{~N})$ & $\%$ & OR & $95 \% \mathrm{CI}$ & $P$ value \\
\hline \multicolumn{8}{|l|}{ Genotypes** } \\
\hline $\mathrm{C} / \mathrm{C}$ & (216) & 43 & (167) & 49 & 1 & & \\
\hline $\mathrm{C} / / \mathrm{T}$ & (178) & 36 & (140) & 41 & 1.46 & & 0.108 \\
\hline $\mathrm{T} / \mathrm{T}$ & (103) & 21 & (32) & 10 & 8.1 & $2.5(1.6-3.8)$ & 0.0001 \\
\hline $\mathrm{C} / \mathrm{C}$ and $\mathrm{T} / \mathrm{T}$ & (281) & 57 & (172) & 51 & 1.7 & $1.14-2.6$ & 0.098 \\
\hline \multicolumn{8}{|l|}{ Alleles } \\
\hline C & (610) & 0.6136 & (474) & 0.6991 & 0.68 & $0.55-0.84$ & 0.0003 \\
\hline $\mathrm{T}$ & (384) & 0.3864 & (204) & 0.3009 & 1.46 & $1.18-1.80$ & 0.0003 \\
\hline
\end{tabular}

Table 5. Associations of the $677 T T$ genotype of the C677T polymorphism of the MTHFR gene with more than one variable among the general characteristics of the $\mathrm{BC}$ patients.

\begin{tabular}{lcccccccc}
\hline & B & SD & Wald & df & P & OR & 95\%CI \\
\cline { 3 - 8 } & & & & & & & Low & Upper \\
\hline Alcohol consumption & -0.883 & 0.374 & 5.580 & 1 & 0.018 & 0.414 & 0.199 \\
SGOT & -1.020 & 0.429 & 5.653 & 1 & 0.017 & 0.361 & 0.156 & 0.860 \\
Constant & -1.119 & 0.126 & 78.975 & 1 & 0.000 & 0.327 & & \\
\hline
\end{tabular}

Variables included in the analysis: dependent: BC patients classified by W/ins-Ins/Ins genotype; independent: personal medical history, menarche ranging from 7-10 years, 11-13 years, or 14-18 years; menopause, pregnancies, breastfeeding, oral contraceptive use, tobacco and alcohol consumption, HF, HF type: BC, DM, AH, DM-AH-cancer, a BMI of 18.5-24.9, $\geq 25-29.9, \geq 30-34.9$, or $\geq 35->40$, lymph node status, metastasis, response to chemotherapy, and laboratory tests (HB, HTO, platelets, leukocytes, urea, SGOT, SGPT, LDH, ALP, GGT, and glucose).

\section{DISCUSSION}

$\mathrm{BC}$ is a multifactorial disease with a complex etiology and is considered to constitute a major public health problem in industrialized countries. In Mexico, the incidence of BC has increased over the last decade, and it is currently one of the leading causes of death in working age women (Knaul et al., 2009; Miller et al., 2010; Chávarri et al., 2012; Gómez Flores et al., 2013; Ramírez et al., 2013; Gallegos et al., 2014). These facts are consistent with the observations made in the current study, in which the average age of BC patients was $53.26( \pm 11.6)$ years. Oral contraceptive use, abortion, menopause, and family history of cancer were found to be risk factors. In addition, breastfeeding and alcohol consumption served as protective factors; these associations are consistent with those observed previously in multiple studies (Martin and Weber, 2000; Naieni et al., 2007; Knaul et al., 2009; Miller et al., 2010; Macciò and Madeddu, 2011; Abdulrahman and Rahman, 2012; Chávarri et al., 2012; Gómez Flores et al., 2013; Ramírez et al., 2013; Gallegos et al., 2014).

Furthermore, when the groups were stratified by tumor stage (stages I-II or III-IV), followed by comparison with the clinical and biochemical characteristics of $\mathrm{BC}$; obesity grade II, metastasis to the lymph nodes, metastasis, and tobacco consumption emerged as risk factors. In this context, these factors have been previously associated with BC (Davoodi et al., 2013; Greer et al., 2014; Nyante et al., 2014). In fact, there are several theories that attempt 
to explain the association of obesity with $\mathrm{BC}$, which involve the roles of leptin, insulin, adipocytes, and other molecules that mediate the inflammatory process, peripheral circulating estrogens, and metabolic syndrome; these may in turn activate molecular processes that are mitogenic in breast epithelial cells and thereby stimulate neoplasia (Gómez Flores et al., 2013; Ramírez et al., 2013; Gallegos et al., 2014).

The genetic regulation of folate metabolism in cancer has been the focus of many investigations, as this has been thought to influence carcinogenesis via DNA hypomethylation of key regulatory genes, as well as through the misincorporation of uracil into DNA leading to double-strand breaks and chromosomal aberrations (Kamdar et al., 2011; Gallegos et al., 2013). The presence of certain polymorphisms in genes involved in folate metabolism, such as MTHFR, might cause deficiencies in enzyme activity leading to inadequate folate metabolism and hypomethylation of DNA, which may trigger neoplastic processes (Sharp and Little, 2004; Kamdar et al., 2011; Gallegos et al., 2013). Association studies have been performed to identify genetic variants associated with BC susceptibility, including in the MTHFR enzyme, which plays an important role in DNA methylation and the provision of nucleotides for DNA synthesis. The MTHFR C677T and A1298C polymorphisms, the variants of which produce a decreased catalytic activity of MTHFR and subsequent increased availability of 5,10-MeTHF and SAM, have been extensively studied in relation to BC (Hosseini et al., 2011; Papandreou et al., 2012; Liang et al., 2014; Weiwei et al., 2014). However, findings from these studies have been inconsistent (Akram et al., 2012).

The allele frequencies of the C677T polymorphism in our control group were similar to those previously reported in Mexico (Davalos et al., 2000; Esfahani et al., 2003; Gueant et al., 2006; Gallegos et al., 2008, 2009). However, little is known about the association of this polymorphism with BC. In this study, the genotypic frequency of the homozygous MTHFR 677TT polymorphism variant was $10 \%$ in controls, and $21 \%$ in patients with $\mathrm{BC}$ with associated risk factor. Papandreou et al. (2012) detected an association for the C677T polymorphism with $\mathrm{BC}$ after adjustment for age $(\mathrm{OR}=1.76 ; 95 \% \mathrm{CI}=0.92-3.42)$. Weiwei et al. (2014) observed that women with the MTHFR 677TT genotype had a significantly increased risk of $\mathrm{BC}$, with ORs $(95 \% \mathrm{CI})$ of $1.8(1.08-2.27)$. Additionally, folate intake $<450 \mu \mathrm{g} /$ day along with the MTHFR 667TT genotype was associated with a higher risk of $\mathrm{BC}(\mathrm{OR}=2.45 ; 95 \% \mathrm{CI}=$ 1.09-5.82; $\mathrm{P}=0.02$ ); similarly, subjects with vitamin $\mathrm{B} 6$ intake $<0.84 \mathrm{mg} /$ day and the $M T H F R$ $667 \mathrm{~T}$ allele was correlated with a marginally increased risk of BC. Liang et al. (2014) in a meta-analysis found that the MTHFR C677T polymorphism was significantly associated with $\mathrm{BC}$ risk in the Chinese population.

In this study, we further observed an inverse association of the 677TT genotype in patients with moderate alcohol consumption and high levels of SGOT and BC. The relationship between alcohol consumption and cancer is complex and has been associated with menopausal status, and with folate intake that contributes to or interrupts one-carbon metabolism (Ulrich et al., 1999). Ulrich et al. (1999) observed that an increased risk for cancer with increasing alcohol consumption was observed only among those with the CC genotype $(\mathrm{P}=0.005)$; among those with the TT genotype, those with moderate alcohol consumption were at lowest risk. This led to the conclusion that the nutrients involved in the MTHFR metabolic pathway might modify the relationship between the MTHFR C677T polymorphism and colorectal adenomas. Bailey (2003) described that a higher folate intake, to potentially reduce an elevated risk for $\mathrm{BC}$, is associated with alcohol consumption; and observed a significant $\mathrm{BC}$ risk reduction of $45 \%$ among women who consumed $\geq 15 \mathrm{~g} /$ day of alcohol with a total folate intake of $\geq 600 \mu \mathrm{g} /$ 
day, (compared with an intake of 150-299 $\mu \mathrm{g} /$ day). The inverse association between plasma folate and $\mathrm{BC}$ risk was highly significant among women consuming $\geq 15 \mathrm{~g} / \mathrm{day}$ of alcohol, in contrast with that of women consuming $<15 \mathrm{~g} /$ day. In women who consumed $\geq 15 \mathrm{~g} /$ day of alcohol and whose plasma folate was in the highest quintile, the BC risk was significantly reduced relative to women with the lowest plasma folate concentrations. These findings indicated that moderate quantities of alcohol (1-2 drinks/day) accounted for the risk associated with alcohol consumption, and that adequate folate status is particularly important for women at higher risk for $\mathrm{BC}$ because of moderate alcohol consumption. Unfortunately, the folate status and dietary intake of patients with $\mathrm{BC}$ were not analyzed in this study.

We also observed an association of the 677TT genotype as a protective factor in patients with high levels of SGOT. In this respect, the relation between a high level of SGOT and BC is complex: elevated SGOT has been associated with several factors, which include alcohol consumption, metastasis, diabetes, myocardial infarction, diet, and chemotherapy. Our observation could possibly be explained by the intersection of SGOT activity with many metabolic pathways, as its substrates are involved in amino acid metabolism, the urea cycle, and the tricarboxylic acid cycle. Because tumor cells have greater energy requirements than non-cancerous cells, there is an increased dependence on this shuttle activity. A recent study on $\mathrm{BC}$ reported that inhibitors of SGOT suppressed the proliferation of an invasive $\mathrm{BC}$ cell line, and that ectopic expression of SGOT conferred resistance, indicating that this enzyme might be a good target for pharmacological intervention (Ugochukwu et al., 2010; Ramírez et al., 2013). According to this model, the blood enzymes, SGOT and glutamic pyruvic transaminase (SGPT), would be able to metabolize glutamate in peripheral blood (Gómez Flores et al., 2013), leading to a decrease in the level of this amino acid (Campos et al., 2011). SGOT, using oxaloacetate as co-substrate, is able to convert glutamate into 2-ketoglutarate and aspartate. SGPT converts glutamate into 2-ketoglutarate and alanine, using pyruvate as co-substrate. Therefore the properties of these enzymes to metabolize glutamate in blood shows that they could be used as new neuroprotective tools against excitotoxic neuronal injury after ischemic stroke (Campos et al., 2011). Consistent with this, Campos et al. (2011) observed an association between high blood SGOT and SGPT levels and positive outcome in ischemic stroke patients. Similarly, Babyshkina et al. (2013) observed a better progression-free survival in premenopausal patients with BC carrying the MTHFR 677TT genotype. In contrast, Shrubsole et al. (2005) found that carrying the $677 \mathrm{~T}$ allele was associated with a non-significant increased risk of death for subjects with late stage disease (stages III-IV) $(\mathrm{OR}=1.80 ; 95 \% \mathrm{CI}=0.79-4.14$ for TT $v s \mathrm{CC}, \mathrm{P}=0.15$ ), particularly among those who had survived past the second year (OR $=2.97 ; 95 \% \mathrm{CI}=1.10-7.98, \mathrm{P}=0.04)$. Zhu et al. $(2013)$, however, in a meta-analysis evaluating the influence of MTHFR polymorphisms on the clinical response to chemotherapy in lung cancer, observed that the MTHFR 677TT genotype could have a better response to platinumbased chemotherapy in the recessive model, and concluded that the MTHFR 677TT genotype might influence the clinical response to platinum-based chemotherapy in advanced non-small cell lung cancer (NSCLC).

Chemosensitivity of patients with $\mathrm{BC}$ differs from person to person, which reflects limited advances in our understanding of the molecular mechanisms underlying breast carcinogenesis and the individual susceptibility to this disease. A growing body of evidence suggests that single nucleotide polymorphisms (SNPs) can help elucidate individual differences in susceptibility and sensitivity to cytotoxic drugs in BC (Gallegos et al., 2008; Ramírez et al., 2013; Zhu et al., 2013). Aberrant DNA methylation is recognized as being a common feature 
of human neoplasia, with $\mathrm{CpG}$ island hypermethylation and global genomic hypomethylation occurring simultaneously in tumors. Because it affects the methylation of DNA and tumor suppressor genes, the MTHFR polymorphism could potentially modulate the efficacy of cytotoxic agents (Gallegos et al., 2008, 2009; Zhu et al., 2013).

We also observed an association of the 677TT genotype as a protective factor in chemotherapy response in patients with $\mathrm{BC}$ who consumed alcohol, and had high level SGOT, and a triple negative classification. However, there are no studies available addressing the influence of the 677TT genotype as a protective factor in chemotherapy response in patients with BC. In respect to this, it has been observed that the MTHFR 677TT genotype also affects tumor response to fluorouracil (5-FU) and methotrexate (MTX) chemotherapies, in that patients with the 677TT genotype responded better than did those with other genotypes (Taub et al., 2002; Alberola et al., 2004). Babyshkina et al. (2013) observed a significant correlation with a better progression-free survival in premenopausal patients with the MTHFR 677TT genotype.

Folate metabolism can likely influence the chemotherapy response in addition to other factors, such as a known presence of metastatic nodes, tumor markers, menopause, the time of diagnosis, tumor stage, and treatment resistance (Sharp and Little, 2004; Knaul et al., 2009; Gómez Flores et al., 2013). This response might be affected by polymorphisms in the MTHFR gene that could cause a dysregulation of MTHFR activity, producing changes in DNA and subsequently participating in neoplastic progression. The chemotherapeutic agents 5-FU, capecitabine, and MTX mainly act as anti-folate agents, resulting in the depletion of metabolically active pools of tetrahydrofolate cofactors with a suppression of folate-dependent synthesis of DNA, RNA, and protein; this is considered to be their main mechanism of action. Thus, it is conceivable that alterations in reduced folate pools may lead to altered 5-FU, capecitabine, and MTX sensitivities. The MTHFR C677TT genotype has been shown to reduce folates, which might consequently produce hyperhomocysteinemia due to folate pool imbalances (Taub et al., 2002).

Our results show that the frequencies of the MTHFR 677TT genotype are significantly different in controls $v s$ patients with BC. The protective association was also evident in patients with a positive chemotherapy response who had consumed alcohol and had high SGOT level and triple negative classifications. The MTHFR 677TT genotype might therefore contribute significantly to $\mathrm{BC}$ susceptibility in the analyzed Mexican population sample. Further studies, however, are required to confirm or reject these observations.

\section{ACKNOWLEDGMENTS}

Research supported by FIS/IMSS/PROT/G13/1231 and Centro de Investigación Biomédica de Occidente, IMSS. We thank Dr. Efrain Salas and nurses from UMAE Hospital de Gineco-Obstetricia, CMNO, IMSS for facilitating sample collection.

\section{REFERENCES}

Abdulrahman GO Jr and Rahman GA (2012). Epidemiology of breast cancer in Europe and Africa. J. Cancer Epidemiol. 2012: 915610.

Akram M, Malik FA and Kayani MA (2012). Mutational analysis of the MTHFR gene in breast cancer patients of Pakistani population. Asian Pac. J. Cancer Prev. 13: 1599-1603.

Alberola V, Sarries C, Rosell R, Taron M, et al. (2004). Effect of the methylenetetrahydrofolate reductase C677T polymorphism on patients with cisplatin/gemcitabine-treated stage IV non-small-cell lung cancer. Clin. Lung Cancer 5: $360-365$. 
Babyshkina N, Malinovskaya E, Nazarenko M, Koval M, et al. (2013). The effect of folate-related SNPs on clinicopathological features, response to neoadjuvant treatment and survival in pre- and postmenopausal breast cancer patients. Gene 518: 397-404.

Bailey LB (2003). Folate, methyl-related nutrients, alcohol, and the MTHFR 677C $\rightarrow$ T polymorphism affect cancer risk: intake recommendations. J. Nutr. 133: 3748S-3753S.

Campos F, Rodríguez M, Castellanos M, Arias S, et al. (2011). Blood levels of glutamate oxaloacetate transaminase are more strongly associated with good outcome in acute ischaemic stroke than glutamate pyruvate transaminase levels. Clin. Sci. 121: 11-17.

Chávarri Y, Villarreal C, Liedke PE, Knaul F, et al. (2012). Breast cancer in Mexico: a growing challenge to health and the health system. Lancet Oncol. 13: e335-343.

Davalos IP, Olivares N, Castillo MT, Cantu JM, et al. (2000). The C677T polymorphism of the methylenetetrahydrofolate reductase gene in Mexican mestizo neural-tube defect parents, control mestizo and native populations. Ann. Genet. 43: 89-92.

Davoodi SH, Malek T, MalekshahiA, Shahbazi R, et al. (2013). Obesity as an important risk factor for certain types of cancer. Iran J. Cancer Prev. 6: 186-194.

Esfahani ST, Cogger EA and Caudill MA (2003). Heterogeneity in the prevalence of methylenetetrahydrofolate reductase gene polymorphisms in women of different ethnic groups. J. Am. Diet. Assoc. 103: 200-207.

Gallegos MP, Figuera LE, Delgado JL, Puebla AM, et al. (2008). The MTHFR polymorphism C677T in adult patients with acute lymphoblastic leukemia is associated with an increased prevalence of cytogenetic abnormalities. Blood Cells Mol. Dis. 40: 244-245.

Gallegos MP, García JE, Figuera LE, Puebla AM et al. (2009). Association of the $677 \mathrm{C} \rightarrow$ T polymorphism in the MTHFR gene with colorectal cancer in Mexican patients. Cancer Genomics Proteomics 6: 183-188.

Gallegos MP, Borjas C, Zúñiga GM, Figuera LE, et al. (2013). Pathophysiology of Acute Lymphoblastic Leukemia. In: Clinical Epidemiology of Acute Lymphoblastic Leukemia - From the Molecules to the Clinic (Mejia-Arangure JM, ed.). InTech, Croatia.

Gallegos MP, Figuera LE, Ramos MC, Salas E, et al. (2014). The association between the 844ins68 polymorphism in the CBS gene and breast cancer. Arch. Med. Sci. 10: 1214-1224.

Gómez Flores L, Escoto A, Puebla AM, Figuera LE, et al. (2013). Association of the tumor necrosis factor-alpha -308G $>$ A polymorphism with breast cancer in Mexican women. Genet. Mol. Res. 12: 5680-5693.

Greer L, Rosman M, Charles W, Liang W, et al. (2014). A prediction model for the presence of axillary lymph node involvement in women with invasive breast cancer: a focus on older women. Breast J. 20:147-153. Doi: 10.

Gueant RM, Gueant JL, Debard R, Thirion S, et al. (2006). Prevalence of methylenetetrahydrofolate reductase 677T and $1298 \mathrm{C}$ alleles and folate status: a comparative study in Mexican, West African, and European populations. Am. J. Clin. Nutr. 83: 701-707.

Hosseini M, Houshmand M and Ebrahimi A (2011). MTHFR polymorphisms and breast cancer risk. Arch. Med. Sci. 7 : 134-137.

Isotalo PA and Donnelly JG (2000). Prevalence of methylenetetrahydrofolate reductase mutations in patients with venous thrombosis. Mol. Diagn. 5: 59-66.

Kamdar KY, Krull KR, El RA, Brouwers P, et al. (2011). Folate pathway polymorphisms predict deficits in attention and processing speed after childhood leukemia therapy. Pediatr. Blood Cancer 57: 454-460.

Kluijtmans LA, Kastelein JJ, Lindemans J, Boers GH, et al. (1997). Thermolabile methylenetetrahydrofolate reductase in coronary artery disease. Circulation 96: 2573-2577.

Knaul FM, Nigenda G, Lozano R, Arreola H, et al. (2009) Breast cancer in Mexico: an urgent priority. Salud Publica Mex. 51: s335-s344. Leukemia 16: 764-765.

Liang H, Yan Y, Li T, Li R, et al. (2014) Methylenetetrahydrofolate reductase polymorphisms and breast cancer risk in Chinese population: a meta-analysis of 22 case-control studies. Tumour Biol. 35: 1695-1701.

Macciò A and Madeddu C (2011). Obesity, inflammation, and postmenopausal breast cancer: therapeutic implications. Sci. World J. 11: 2020-2036.

Martin AM and Weber BL (2000). Genetic and hormonal risk factors in breast cancer. J. Natl. Cancer Inst. 92: 1126-1135.

Miller SA, Dykes DD and Polesky HF (1988). A simple salting out procedure for extracting DNA from human nucleated cells. Nucleic Acids Res. 16: 1215.

Miller JW, King JB, Joseph DA and Richardson LC (2010). Breast cancer screening among adult women-behavioral risk factor surveillance system, United States, 2010. MMWR Morb. Mortal. Wkly. Rep. 61: 46-50.

Naieni KH, Ardalan A, Mahmoodi M, Motevalian A, et al. (2007). Risk factors of breast cancer in north of Iran: a casecontrol in Mazandaran Province. Asian Pac. J. Cancer Prev. 8: 395-398. 
Nyante S, Gierach G, Dallal C, Freedman N, et al. (2014). Cigarette smoking and postmenopausal breast cancer risk in a prospective cohort. Br. J. Cancer 110: 2339-2347. OMIM 607093. [http://omim.org/entry/607093].

Papandreou CN, Doxani C, Zdoukopoulos N, Vlachostergios PJ, et al. (2012). Evidence of association between methylenetetrahydrofolate reductase gene and susceptibility to breast cancer: a candidate-gene association study in a South-eastern European population. DNA Cell Biol. 31: 193-198.

Ramírez R, Figuera LE, Puebla AM, Delgado JI, et al. (2013) Intron 4 VNTR (4a/b) polymorphism of the endothelial nitric oxide synthase gene is associated with breast cancer in Mexican women. J. Korean Med. Sci. 28: 1587-1594.

Sanguinetti CJ, Dias NE and Simpson AJ (1994). Rapid silver staining and recovery of PCR products separated on polyacrylamide gels. Biotechniques 17: 914-921.

Sharp L and Little J (2004) Polymorphisms in genes involved in folate metabolism and colorectal neoplasia: a HuGE review. Am. J. Epidemiol. 159: 423-443.

Shrubsole MJ, Shu XO, Ruan ZX, Cai Q, et al. (2005). MTHFR genotypes and breast cancer survival after surgery and chemotherapy: a report from the Shanghai Breast Cancer Study. Breast Cancer Res. Treat. 91: 73-79.

Siegel R, Desantis C, Virgo K, Stein K, et al. (2012). Cancer treatment and survivor ship statistics, 2012. CA Cancer J. Clin. 62: 220-241.

Taub JW, Matherly LH, Ravindranath Y, Kaspers GJ, et al. (2002). Polymorphisms in methylenetetrahydrofolate reductase and methotrexate sensitivity in childhood acute lymphoblastic leukemia. Leukemia 16: 764-765.

Ugochukwu E, Pilka E, Cooper C, Bray JE et al. (2010). GOT1 (Glutamate Oxaloacetate Transminase 1). SGC Laboratories. Available at [http://www.thesgc.org/sites/default/files/activeISee/GOT1A_3ii0_v1_372a/Annotation. html]. Accessed June, 2014.

Ulrich CM, Kampman E, Bigler J, Schwartz SM, et al. (1999). Colorectal adenomas and the C677T MTHFR polymorphism: evidence for gene-environment interaction? Cancer Epidemiol. Biomarkers Prev. 8: 659-668.

Weiwei Z, Liping C and Dequan L (2014). Association between dietary intake of folate, vitamin B6, B12 \& MTHFR, MTR Genotype and breast cancer risk. Pak. J. Med. Sci. 30: 106-110.

World Health Organization (2004). Appropriate body-mass index for Asian populations and its implications for policy and intervention strategies. Ginebra (Suiza). The Lancet 363: 157-163.

Zetterberg H, Regland B, Palmér M, Ricksten A, et al. (2002). Increased frequency of combined methylenetetrahydrofolate reductase C677T and A1298C mutated alleles in spontaneously aborted embryos. Eur. J. Hum. Genet. 10: 113-118.

Zhu N, Gong Y, He J, Xia J, et al. (2013). Influence of methylenetetrahydrofolate reductase C677T polymorphism on the risk of lung cancer and the clinical response to platinum-based chemotherapy for advanced non-small cell lung cancer: an updated meta-analysis. Yonsei Med. J. 54: 1384-1393. 